\title{
BMJ Open How often will midwives and obstetricians experience obstetric emergencies or high-risk deliveries: a national cross-sectional study
}

\author{
Stinne Høgh (1) , ${ }^{1}$ Line Thellesen, ${ }^{1}$ Thomas Bergholt, ${ }^{1}$ Ane Lilleøre Rom, ${ }^{2}$ \\ Marianne Johansen, ${ }^{1}$ Jette Led Sorensen ${ }^{2,3}$
}

To cite: Høgh S, Thellesen L, Bergholt T, et al. How often will midwives and obstetricians experience obstetric emergencies or high-risk deliveries: a national crosssectional study. BMJ Open 2021;11:e050790. doi:10.1136/ bmjopen-2021-050790

- Prepublication history for this paper is available online. To view these files, please visit the journal online (http://dx.doi. org/10.1136/bmjopen-2021050790).

Received 06 March 2021 Accepted 20 October 2021

Check for updates

(C) Author(s) (or their employer(s)) 2021. Re-use permitted under CC BY-NC. No commercial re-use. See rights and permissions. Published by BMJ.

${ }^{1}$ Department of Obstetrics, Copenhagen University Hospital - Rigshospitalet, Copenhagen, Denmark

2Juliane Marie Centre for Children, Women and Reproduction Section 4074, Rigshospitalet, University of Copenhagen, Copenhagen, Denmark

${ }^{3}$ Department of Clinical Medicine, University of Copenhagen, Copenhagen, Denmark

\section{Correspondence to} Dr Stinne Høgh, Department of Obstetrics, University of Copenhagen - Rigshospitalet,

Copenhagen, Denmark; stinne.hoegh@regionh.dk

\section{ABSTRACT}

Objective To estimate how often midwives, specialty trainees and doctors specialised in obstetrics and gynaecology are attending to specific obstetric emergencies or high-risk deliveries (obstetric events). Design A national cross-sectional study. Setting All hospital labour wards in Denmark. Participants Midwives ( $n=1303)$, specialty trainees $(\mathrm{n}=179)$ and doctors specialised in obstetrics and gynaecology $(n=343)$ working in hospital labour wards $(\mathrm{n}=21)$ in Denmark in 2018.

Methods Categories of obstetric events comprised of Apgar score $<7 / 5$ min, eclampsia, emergency caesarean sections, severe postpartum haemorrhage, shoulder dystocia, umbilical cord prolapse, vaginal breech deliveries, vaginal twin deliveries and vacuum extraction. Data on number of healthcare professionals were obtained through the Danish maternity wards, the Danish Health Authority and the Danish Society of Obstetricians and Gynaecologists. We calculated the time interval between attending each obstetric event by dividing the number of events occurred with the number of healthcare professionals.

Outcome measures The time interval between attending a specific obstetric event.

Results The average time between experiencing obstetric events ranged from days to years. Emergency caesarean sections, which occur relatively frequent, were attended on average every other month by midwives, every 9 days for specialty trainees and every 17 days by specialist doctors. On average, rare events like eclampsia were experienced by midwives only every 42 years, every 6 years by specialty trainees and every 11 years by specialist doctors. Conclusions Some obstetric events occur extremely rarely, hindering the ability to obtain and maintain the clinical skills to manage them through clinical practice alone. By assessing the frequency of a healthcare professionals attending an obstetric emergency, our study contributes to assessing the need for supplementary educational initiatives and interventions to learn and maintain clinical skills.

\section{INTRODUCTION}

In high-income countries, most pregnancies have good outcomes. Obstetric emergencies
Strengths and limitations of this study

- The first study to calculate how often healthcare professionals can expect to attend specific obstetric emergencies or high-risk deliveries in clinical real life.

- The incidence of the obstetric events was based on a large data source comprising 465919 deliveries during an 8-year period.

- The study comprised medical doctors and midwives working at all the labour wards throughout Denmark.

- Our findings are based on average estimates, and results may be skewed by national variation in clinical experience and interest as well as regional clinical practice.

- Differences in the size and level of specialisation in the labour wards may influence the frequency of experiencing the events.

like eclampsia, severe postpartum haemorrhage, shoulder dystocia and umbilical cord prolapse are fortunately rare obstetric events. ${ }^{1}$ These potentially life-threatening emergencies often occur unexpectedly and require immediate action by healthcare professionals $^{23}$ and may entail tragic consequences such as death or serious morbidity in women and/or newborns. ${ }^{4-6}$

Obstetric emergencies often occur in extremely stressful settings that require highly professional communication and teamwork skills in order to take appropriate action. Similarly, high-risk deliveries, like vaginal twin or breech deliveries, also require highly specialised skills in healthcare professionals attending the event to ensure good outcomes. $^{7-10}$

Healthcare professionals must be qualified to manage these emergencies and highrisk deliveries (obstetric events) to ensure patient safety. However, audit-based studies have shown how these events are not always 
managed according to well-known, evidence-based standards of obstetric care..$^{5611-15}$ An analysis of 127 cases of peripartum hypoxic brain injuries in claims registered by the Danish Patient Insurance Association concluded that all of the injuries were potentially avoidable if standard obstetric care had been applied. ${ }^{11}$ Substandard care was also found in $42 \%$ of deliveries with low Apgar scores in Sweden, ${ }^{12}$ and in the UK in nearly half of intrapartum stillbirths and in half of the intrapartum-related neonatal deaths. ${ }^{13}$ Studies of maternal deaths in the UK found that substandard care during pregnancy or delivery had occurred in $29 \%$ of cases. ${ }^{16}$

Clinical negligence is devastating to the family involved, just as the healthcare professionals involved may experience emotional, behavioural and cognitive consequences in terms of anxiety, depression symptoms, ${ }^{17}$ post-traumatic stress disorder ${ }^{18}$ and loss of professional confidence, leading to self-doubt, isolation, practising defensive medicine and fear. ${ }^{19}{ }^{20}$ Healthcare professionals involved in cases of clinical negligence are often referred to as second victims. ${ }^{17} 1821$ Moreover, cases of clinical negligence often entail high litigation and future healthcare costs. ${ }^{22}{ }^{23}$ Hence, to safeguard the women and prevent avoidable harm due to substandard obstetric care and subsequent litigation and healthcare costs, the level of quality of managing obstetric events must be improved. It is well known that we are challenged in obtaining and maintaining the necessary clinical skills to manage rare obstetric events in 'real work-life'. However, no study has previously quantified this challenge.

This study aimed to estimate how often midwives, specialty trainees and doctors specialised in obstetrics and gynaecology on average can expect to attend and get involved in obstetric emergencies and high-risk deliveries.

\section{METHODS}

\section{Study design and setting}

We conducted a national cross-sectional study that included midwives, specialty trainees and doctors specialised in obstetrics and gynaecology (specialist doctors) working clinically in hospital-based labour wards in Denmark in 2018. There are approximately 60000 deliveries in Denmark annually, with 96\%-98\% occurring at public hospitals and $2 \%-3 \%$ as home births. ${ }^{24}$

In 2018, Denmark had 21 labour wards, all of them staffed with in-house, on-call specialist doctors in obstetrics and gynaecology as well as anaesthesiology specialist doctors. The wards vary in size and specialty level from highly specialised tertiary referral centres (the largest with about 7000 deliveries per year) to small departments with only 600-1000 deliveries per year. All low-risk deliveries are attended by midwives often accompanied by midwifery students, during the active phase of labour. Specialist doctors and specialty trainees are only involved when complications arise. ${ }^{25}$ In high-risk deliveries, specialist doctors and specialty trainees are always involved, and managing the delivery is a collaborative team effort between the midwife, specialty trainee and specialist doctor.

\section{Population}

\section{Eligible for inclusion}

Midwives, specialty trainees and specialist doctors in obstetrics and gynaecology working clinically in a Danish labour ward in 2018 were eligible.

\section{Midwives}

In Denmark, midwives must earn a bachelor's degree in midwifery. During the 3.5-year programme, students spend half of their time in clinical placements, for example, midwifery centres, labour wards, antenatal wards and postnatal wards. Most midwives work in shifts. When caring for women giving birth, midwives are qualified and authorised to work independently, though in collaboration with a doctor when complications arise. This study collected data on midwives working predominantly on labour wards. All the midwives were included as if they were working full time.

\section{Specialty trainees}

In this study, specialty trainee refers to doctors in their 5-year postgraduate medical specialist training programme in obstetrics and gynaecology. Mandatory general courses, specialty-specific courses and research training are also part of the curriculum. On graduation, they are qualified to examine and treat $90 \%$ of the conditions in the specialty. ${ }^{26}$

\section{Specialist doctors}

In this study, specialist doctors refer to individuals who have completed their specialty training in obstetrics and gynaecology. A large proportion of specialist doctors are subspecialised in either obstetrics or gynaecology, however with both groups participating in night shifts on the labour wards. Specialist doctors on call have full responsibility for the labour ward and supervise specialty trainees. According to the Danish Health Association, labour wards must, as a minimum, always have a specialist doctor or a last year specialty trainee on duty. We included only specialist doctors, working in hospitals, who also did night shifts on the labour wards.

The average work week for full-time healthcare professionals is 37 hours in Denmark. All healthcare professionals included in this study participated in obstetric night shifts.

\section{Data collection}

Healthcare professionals

Data on the number of obstetric healthcare professionals were collected in 2018 to obtain more valid data than would be possible had data been collected for previous years. Data on healthcare professionals were retrieved in various ways.

\section{Midwives}

The heads of midwifery in maternity units across Denmark were contacted by email in October 2018 and asked to 
provide data on the number of midwives employed in their labour wards.

\section{Specialty trainees}

Data on the number of specialty trainees was obtained through the Danish Health Authority, which regulates the number of specialty trainees. ${ }^{27} 28$

\section{Specialist doctors}

The Danish Society of Obstetricians and Gynaecologists furnished data on the number of specialist doctors.

The data on the number of healthcare professionals working in labour wards were validated with data from a national quality assurance project called Safe Deliveries. ${ }^{29}$

\section{Obstetric events}

In this study, the term obstetric events refers to both obstetric emergencies and high-risk deliveries, the former defined as serious, unexpected and potentially life-threatening conditions that may occur in pregnancy, during labour or after delivery and that require immediate action by healthcare professionals, ${ }^{2}{ }^{3}$ while the latter involve actual or potential hazards to the health or well-being of the mother or fetus. The incidence of obstetric events used in this study was calculated based on data from 465919 deliveries from 2008 to 2015 and are reported in another paper. ${ }^{1}$ Data were retrieved from the Danish Medical Birth Registry, which was established in 1973 and contains information on all deliveries in Denmark, including data on the mother, child, pregnancy and delivery. ${ }^{30}$ Diagnoses are registered using International Classification of Diseases (ICD) codes, 10th revision, ${ }^{31}$ and surgery is coded by the Danish version of the NOMESCO Classification of Surgical Procedures (NCSP) ${ }^{32}$ In Denmark, all individuals have a unique personal identification number, making it possible to conduct valid registry-based studies. Diagnoses in the Danish Medical Birth Registry have been validated, and the authors found that the more severe the condition, the higher the validity of the coding. ${ }^{33}$

The obstetric events included in our study were: Apgar score <7/5 min (ICD-10: DVA00-DVA06), eclampsia (ICD-10: O151, O152 and O159), emergency caesarean section (NCSP: KMCA10A, KMCA10D and KMCA10E), severe postpartum haemorrhage $(\geq 1000 \mathrm{~mL})$ (ICD-10: O072, only $\geq 1000 \mathrm{~mL}$ ), shoulder dystocia (ICD-10: O660, NCSP: KMAH15), umbilical cord prolapse (ICD-10: O690), vaginal breech delivery (NCSP: DUP07-DUP11 and DUP16 without caesarean sections, NCSP: KMCA10), vaginal twin delivery (ICD-10: O300, without caesarean sections, NCSP: KMCA10) and instrumental delivery by vacuum extraction (NCSP: KMAE00, KMAE03 and KMAE96). These critical events may result in maternal and neonatal mortality and morbidity and are often subjects of clinical training. ${ }^{457115}$ Moreover, obstetric healthcare professionals are expected to safely and expertly manage these events.

\section{Statistical analysis}

The outcome of interest was the estimated average time interval between the expected acquaintance with one obstetric event to the next similar obstetric event divided across the number of midwives, specialty trainees and specialist doctors. We calculated the average time interval between the events by dividing the number of events per year (incidence times the total number of deliveries in 2018) with the number of healthcare professionals in the study (midwives, specialty trainees and specialist doctors, respectively). The result was divided by 12 to calculate the number of months between a potentially experienced event. We based the analysis on the assumption that all healthcare professionals can learn from an event if they are either participating hands-on or are present in the delivery room as an observer or assistant. We, therefore, assumed that one event had a midwife, a specialty trainee and a specialist doctor involved. Statistically, the three groups of healthcare professionals therefore share an event.

Since the estimates constitute average numbers, they are presented as means. Probabilities of experiencing an obstetric emergency were calculated using Microsoft Excel (Microsoft Cooperation V.14.6.6).

\section{Patient or public involvement}

There was no direct patient or public involvement in this study.

\section{RESULTS}

Denmark had 61273 deliveries in 2018. ${ }^{24}$ Table 1 presents data on the number of midwives, specialty trainees and specialist doctors working at one of the 21 hospital labour wards. The number of midwives per labour ward ranged from 13 to 135 .

Table 2 shows the incidences of the obstetric events and the average time interval between experiencing each of the studied obstetric event as midwives, specialty trainees and specialist doctors in obstetrics and gynaecology. These estimates were calculated under the assumption that all healthcare professionals learn from an event if they either participate hands-on, observe the event or act as an assistant.

Six of the obstetric events (eclampsia, Apgar score $<7 / 5$ min, umbilical cord prolapse, singleton vaginal

Table 1 Approximate numbers of obstetric healthcare professionals working in one of the 21 Danish hospital labour wards in 2018

\section{Obstetric healthcare} professionals

Number of healthcare

Midwives professionals

Specialty trainees in obstetrics 1303

and gynaecology

Doctors specialised obstetrics and gynaecology 
Table 2 Estimated time between obstetric emergency or high-risk delivery divided across midwives, specialty trainees and doctors specialised in obstetrics and gynaecology

\begin{tabular}{lllll} 
& & \multicolumn{2}{l}{$\begin{array}{l}\text { Expected time between obstetric events* divided across } \\
\text { healthcare professionals }\end{array}$} \\
\cline { 2 - 5 } Obstetric events†,¥ & Incidence (\%) & Midwives & Specialty trainees & Specialist doctors \\
\hline Eclampsia & 0.05 & 42 years & 6 years & 11 years \\
Umbilical cord prolapse & 0.10 & 21 years & 3 years & 5.5 years \\
Singleton vaginal breech delivery & 0.50 & 4 years & 7 months & 1 year \\
Apgar score $<7 / 5$ min & 0.90 & 2.5 years & 4 months & 8 months \\
Shoulder dystocia & 1.00 & 2 years & 4 months & 7 months \\
Vaginal twin delivery & 1.00 & 2 years & 4 months & 7 months \\
Severe postpartum haemorrhage & 6.40 & 4 months & 17 days & 1 month \\
Vacuum extraction & 7.00 & 4 months & 15 days & 1 month \\
Emergency caesarean section & 12.20 & 2 months & 9 days & 16 days \\
\hline
\end{tabular}

Calculations based on the assumption that all healthcare professionals can learn from an event if they participate hands-on, observe or assist at the event.

${ }^{*}$ Number of events per year are calculated based on number of deliveries in Denmark in 2018 (61 273 deliveries). Numbers are rounded up or down to nearest 0.5 years or months.

†One delivery can be represented more than once at the obstetric events.

$\ddagger$ The obstetric event incidence is based on deliveries in Denmark from 2008 to 2015, with gestational age 20+0 to 45+0. In the event of multiple fetuses in one pregnancy, an event among one or more newborns counts.

breech delivery, shoulder dystocia and vaginal twin delivery) occurred at a low incidence of $0.05 \%-1.00 \%$. Three of the events (severe postpartum haemorrhage, delivery by vacuum extraction and emergency caesarean section) occurred relatively often, with an incidence of $6.4 \%-12.2 \%$. The time interval between the events differed depending on the incidence of the event and the group of healthcare professionals. Midwives experienced eclampsia only every 42 years on average, specialty trainees every 6 years and specialist doctors every 11 years.

The events with relatively high incidence were hence experienced relatively more often. Emergency caesarean section, with an incidence of $12.2 \%$, were experienced, on average, every other month for midwives, every 9 days for specialty trainees and every 17 days for specialist doctors.

Instrumental delivery with vacuum extraction and severe postpartum haemorrhage, with an incidence of $7.0 \%$ and $6.4 \%$, respectively, were, on average, experienced by midwives every 4 months, by specialty trainees every 16 days and by specialist doctors once a month (table 2).

\section{DISCUSSION}

\section{Main findings}

In this Danish national cross-sectional study examining how often an obstetric healthcare professional can expect to be involved in an obstetric emergency or a high-risk delivery, we found that the average time interval between experiencing one of the obstetric events ranged from days to years. Our results show that midwives experienced the studied events less frequently than specialist doctors, and specialty trainees were found to experience the events most frequently.

\section{Strengths and limitations}

This study addressed a gap in the research literature by trying to estimate how often healthcare professionals can expect to experience specific obstetric emergencies or high-risk deliveries in a Danish healthcare setting. A strength of our study is that the incidence of the obstetric events was based on a large data source comprising 465919 deliveries during an 8-year period. The exact number of midwives was difficult to obtain due to diversity in work tasks and work hours. Therefore, we included midwives working both part time and full time on labour wards, which suggests that our results are conservative estimates.

Even though the number of healthcare professionals working on labour wards changes over time due to various organisational, political and economic factors, our results are assumed to be the most valid estimates obtainable as minor variations in the numbers do not change the overall estimates substantially.

We used data on specific obstetric events from existing research, obtained for 2008-2015. ${ }^{1}$ Data on the number of obstetric healthcare professionals were collected for 2018 since data from this year are assumed to be more valid compared with data for previous years due to the possibility of recall bias. Nationally, incidences of obstetric events are fairly consistent over the years. Therefore, we have no reason to believe that the different time periods used may have compromised the validity of our study results. ${ }^{1}$ 
Danish labour wards differ in size and level of specialisation. Consequently, healthcare professionals at large departments with a high level of specialisation will experience the events more often than healthcare professionals at smaller departments and more frequently than our results suggest. Moreover, the time interval between attending the events may vary due to the variations in healthcare professionals' clinical preference as well as differences in regional clinical practice. Finally, data on incidences, for example, vaginal breech deliveries, could be distributed unevenly between the labour wards due to different regional practices.

We assumed that the healthcare professionals may learn from a specific obstetric event if they are either providing care hands-on or are present in the delivery room either as an observer or as an assistant. However, if we base our findings on the assumption that each obstetric event only allow one from each healthcare worker profession, that is, only one midwife, one specialty trainee and one specialist doctor to learn from each event, then the frequency with which each of the attendants may potentially learn from these relative rare obstetric events fall significantly.

\section{Interpretation}

Our results suggest that midwives and specialist doctors can have a lifelong working life and only experience certain severe obstetric emergencies once or twice, if at all. When emergencies occur, however, healthcare professionals are expected to have the skills to manage the event according to well-known, evidence-based standards of obstetric care. As a result, healthcare professionals must always be prepared for obstetric emergencies to occur. Our findings show that it is unrealistic for healthcare professionals to obtain and maintain the competences required to manage rare obstetric events through clinical experience alone. Studies on trainee doctors' experience and confidence in managing vaginal breech deliveries and vaginal twin deliveries show that the confidence increased with increasing number of deliveries attended. $^{3435}$ Furthermore, among trainees who did not intend to offer vaginal breech deliveries and vaginal twin deliveries, in $46 \%$ and $67 \%$, the argument was that they did not have sufficient experience to manage these complex vaginal deliveries. ${ }^{35}$

A common feature of the events studied was that the time interval between emergencies or high-risk deliveries depended on the healthcare professional group, indicating that some groups can acquire the skills based primarily on clinical experience alone. However, alternative educational pathways should be provided for other groups. To improve patient safety, minimise litigation and ameliorate the consequences for the healthcare professionals involved, ensuring that they have the necessary skills to manage obstetric events must be prioritised. ${ }^{22}$

Educational approaches could be video-cases, e-learning, case-based interprofessional learning or simulation-based education. ${ }^{36}$ Simulation-based education, which is a valuable supplement to traditional ways of learning through clinical practices and mentorship, represents one way of ensuring acquisition of clinical skills and maintenance hereof. ${ }^{37}$ Simulation-based training can identify and correct common clinical errors made during emergencies and has been recommended as a valuable standard supplementary to clinical practice in order to improve care provided. ${ }^{23} 3839$ Obstetric emergency simulation-based training has been shown to impact the knowledge, skills and attitudes of healthcare professionals. Moreover, some studies have found that this type of training reduces maternal and neonatal morbidity and mortality, though other studies have failed to show an effect on clinical outcomes. ${ }^{40-44}$

Knowledge and skills deteriorate over time and must be maintained. ${ }^{41} 45{ }^{46}$ Studies show that the level of knowledge falls within 9-15 months after obstetric skills training $^{414} 47$ and some studies suggest that annual obstetric skills training is necessary to combat this decline. ${ }^{4548}$ Our findings allow us to differentiate between the obstetric events that require frequent simulationbased training and the ones that can generally be maintained at a certain level based on daily clinical practice alone. Moreover, our results may indicate which healthcare professionals can rely on maintaining their skills primarily through clinical practice and who needs additional obstetric skills training. However, some argue that training individual groups of healthcare professionals is inadequate, highlighting the importance of including all team members in a multidisciplinary team when training due to the complexity of the skills and the rarity of certain obstetric events. ${ }^{41} 49$

Our results may be relevant in other clinical specialties in which rare clinical emergencies occur that require prompt and professional action by healthcare professionals, for example, abdominal aortic aneurysms in vascular surgery ${ }^{50}$ and paediatric emergency medicine. ${ }^{51}$ Rare events in these medical specialties also represent a challenge in terms of learning the required skills via the traditional apprenticeship model and ongoing clinical work, which is why simulation-based skills training is necessary. ${ }^{52}$

Finally, the results from this study only provide a part of the overall picture of training and maintaining the competences in managing rare complications.

\section{CONCLUSION}

We found that some obstetric emergencies and high-risk deliveries were experienced so infrequently that the clinical skills required to competently manage the events is deemed to be impossible to obtain and maintain in clinical practice alone. Consequently, to enhance patient safety, reduce burnout in healthcare professionals and minimise litigation costs, investing in supplementary training activities is the way forward to improving patient care. In this regard, our study contributes to assessing the need for supplementary educational initiatives. 
Acknowledgements We would like to thank the heads of midwifery from all maternity units in Denmark for providing us with data on the number of midwives employed in their units. We would like to express our deepest gratitude to senior advisor Steen Rasmussen, MSc, MPH, Rigshospitalet, for managing the national registry data from the Danish Medical Birth Registry.

Contributors JLS created the idea. All authors participated in creating the study design. SH was responsible for collecting the data. SH and LT performed the analysis and drafted the initial manuscript. TB, ALR, MJ and JLS reviewed and revised the manuscript for interpretation of data and critical revision of important intellectual content. All authors reviewed and approved the final manuscript as submitted. JLS is the guarantor and accepts full responsibility for the work and/ or the conduct of the study, had access to the data, and controlled the decision to publish.

Funding This work was supported by TrygFonden, grant number 105632. Competing interests None declared.

Patient and public involvement Patients and/or the public were not involved in the design, or conduct, or reporting, or dissemination plans of this research.

Patient consent for publication Not applicable.

Ethics approval Approval was obtained from the Danish Data Protection Agency (file no.: 2012-58-0004). As this is a registry-based study, it is not legally required to obtain ethics approval from the Danish National Research Ethics Committee.

Provenance and peer review Not commissioned; externally peer reviewed.

Data availability statement Data are available on reasonable request. The data that support the findings of this study are available on request from the corresponding author, $\mathrm{SH}$.

Open access This is an open access article distributed in accordance with the Creative Commons Attribution Non Commercial (CC BY-NC 4.0) license, which permits others to distribute, remix, adapt, build upon this work non-commercially, and license their derivative works on different terms, provided the original work is properly cited, appropriate credit is given, any changes made indicated, and the use is non-commercial. See: http://creativecommons.org/licenses/by-nc/4.0/.

ORCID iD

Stinne Høgh http://orcid.org/0000-0002-8712-1088

\section{REFERENCES}

1 Hoegh S, Thellesen L, Christensen KB, et al. Incidences of obstetric outcomes and sample size calculations: a Danish national registry study based on all deliveries from 2008 to 2015. Acta Obstet Gynecol Scand 2020;99:34-41.

2 Committee A. Committee opinion no. 590: preparing for clinical emergencies in obstetrics and gynecology. Obstet Gynecol 2014;123:722-5.

3 Oxford dictionaries, 2018. Available: https://en.oxforddictionaries. com

4 Khan KS, Wojdyla D, Say L, et al. Who analysis of causes of maternal death: a systematic review. Lancet 2006;367:1066-74.

5 Cantwell R, Clutton-Brock T, Cooper G, et al. Saving mothers' lives: reviewing maternal deaths to make motherhood safer: 2006-2008. The eighth report of the Confidential enquiries into maternal deaths in the United Kingdom. BJOG 2011;118 Suppl 1:1-203.

6 Ozimek JA, Eddins RM, Greene N, et al. Opportunities for improvement in care among women with severe maternal morbidity. Am J Obstet Gynecol 2016;215:509.e1-509.e6.

7 Berglund S, Grunewald C, Pettersson H, et al. Risk factors for asphyxia associated with substandard care during labor. Acta Obstet Gynecol Scand 2010;89:39-48.

8 Milsom I, Ladfors L, Thiringer K, et al. Influence of maternal, obstetric and fetal risk factors on the prevalence of birth asphyxia at term in a Swedish urban population. Acta Obstet Gynecol Scand 2002;81:909-17.

9 Hannah ME, Hannah WJ, Hewson SA, et al. Planned caesarean section versus planned vaginal birth for breech presentation at term: a randomised multicentre trial. term breech trial Collaborative group. Lancet 2000;356:1375-83.

10 Barrett JFR, Hannah ME, Hutton EK, et al. A randomized trial of planned cesarean or vaginal delivery for twin pregnancy. $N$ Engl $J$ Med 2013;369:1295-305.

11 Hove LD, Bock J, Christoffersen JK, et al. Analysis of 127 peripartum hypoxic brain injuries from closed claims registered by the Danish patient insurance association. Acta Obstet Gynecol Scand 2008;87:72-5.

12 Berglund $\mathrm{S}$, Pettersson $\mathrm{H}$, Cnattingius $\mathrm{S}$, et al. How often is a low Apgar score the result of substandard care during labour? BJOG 2010;117:968-78.

13 MBRRACE-UK. MBRRACE-UK 2017 perinatal confidential enquiry: term, singleton, intrapartum stillbirth and intrapartum-related neonatal death. Leicester: The Infant Mortality and Morbidity Studies, Department of Health Sciences, University of Leicester, 2017.

14 MBRRACE-UK. Saving lives, improving mothers' care - lessons learned to inform maternity care from the $u k$ and ireland confidential enquiries into maternal deaths and morbidity 2013-15. Oxford: National Perinatal Epidemiology Unit, University of Oxford, 2017.

15 Berglund S, Grunewald C, Pettersson H, et al. Severe asphyxia due to delivery-related malpractice in Sweden 1990-2005. BJOG 2008;115:316-23.

16 Knight M, Bunch K, Tuffnell D. Saving lives, improving mothers' care. lessons learned to inform maternity care from the UK and Ireland confidential enquiries into maternal deaths and morbidity 2015-17. Oxford: National Perinatal Epidemiology Unit, University of Oxford, 2019.

17 Seys D, Wu AW, Van Gerven E, et al. Health care professionals as second victims after adverse events: a systematic review. Eval Health Prof 2013;36:135-62.

18 Wahlberg $\AA$, Andreen Sachs M, Johannesson K, et al. Post-Traumatic stress symptoms in Swedish obstetricians and midwives after severe obstetric events: a cross-sectional retrospective survey. BJOG 2017;124:1264-71.

19 Robertson JH, Thomson AM. An exploration of the effects of clinical negligence litigation on the practice of midwives in England: a phenomenological study. Midwifery 2016;33:55-63.

20 Bourne T, Vanderhaegen J, Vranken R, et al. Doctors' experiences and their perception of the most stressful aspects of complaints processes in the UK: an analysis of qualitative survey data. BMJ Open 2016;6:e011711

21 Wu AW, . Medical error: the second victim. The doctor who makes the mistake needs help too. BMJ 2000;320:726-7.

22 Yau CWH, Leigh B, Liberati E, et al. Clinical negligence costs: taking action to safeguard NHS sustainability. BMJ 2020;368:m552.

23 NHS Litigation Authority. Ten years of maternity claims. An analysis of NHS litigation authority data. London: NHS LA, 2012.

24 National Health Data Authority. Medicinsk Fødselsregister, 2018. Available: https://sundhedsdatastyrelsen.dk/da/registre-og-services/ om-de-nationale-sundhedsregistre/graviditet-foedsler-og-boern/ foedselsregisteret

25 Sundhedsstyrelsen. Anbefalinger for svangreomsorgen. Copenhagen: Sundhedsstyrelsen, 2013.

26 National Board of Health. Postgraduate medical training in Denmark - status and future perspectives. Summary in English. Copenhagen: National Board of Health, 2012.

27 Danish Health Authority. Lægeprognose 2015-2040 Udbuddet AF læger OG speciallæger. Copenhagen: Sundhedsstyrelsen, 2016.

28 Danish Health Authority. Opslåede OG besatte hoveduddannelsesforløb I 2016. Copenhagen: Danish Health Authority, 2017.

29 Thellesen L, Sorensen JL, Hedegaard M, et al. Cardiotocography interpretation skills and the association with size of maternity unit, years of obstetric work experience and healthcare professional background: a national cross-sectional study. Acta Obstet Gynecol Scand 2017;96:1075-83.

30 Langhoff-Roos J, Krebs L, Klungsøyr K, et al. The Nordic medical birth registers-a potential goldmine for clinical research. Acta Obstet Gynecol Scand 2014;93:132-7.

31 World Health Organization. International classification of diseases and related health problems 2016.

32 Nordic Centre for Classification in Healthcare. NOMESCO classification of surgical procedures (NSCP), version 1.16, 2012. Available: https://medinfo.dk/sks/brows.php

33 Bliddal M, Broe A, Pottegård A, et al. The Danish medical birth register. Eur J Epidemiol 2018;33:27-36.

34 Chinnock M, Robson S. Obstetric trainees' experience in vaginal breech delivery: implications for future practice. Obstet Gynecol 2007;110:900-3.

35 Yeoh SGJ, Rolnik DL, Regan JA, et al. Experience and confidence in vaginal breech and twin deliveries among obstetric trainees and new specialists in Australia and New Zealand. Aust N Z J Obstet Gynaecol 2019;59:545-9.

36 Topperzer MK, Roug LI, Andrés-Jensen L, et al. Twelve tips for postgraduate interprofessional case-based learning. Med Teach 2021:1-14. 
37 Cook DA, Hatala R, Brydges R, et al. Technology-enhanced simulation for health professions education: a systematic review and meta-analysis. JAMA 2011;306:978-88.

38 and $\mathrm{ACoO}$ and Gynecologists. Committee opinion no. 590: preparing for clinical emergencies in obstetrics and gynecology. Obstet Gynecol 2014;123:722-5.

39 Gardner R, Raemer DB. Simulation in obstetrics and gynecology. Obstet Gynecol Clin North Am 2008;35:97-127.

40 Bergh A-M, Baloyi S, Pattinson RC. What is the impact of multiprofessional emergency obstetric and neonatal care training? Best Pract Res Clin Obstet Gynaecol 2015;29:1028-43.

41 Merién AER, van de Ven J, Mol BW, et al. Multidisciplinary team training in a simulation setting for acute obstetric emergencies: a systematic review. Obstet Gynecol 2010;115:1021-31.

42 Draycott T, Sibanda T, Owen L, et al. Does training in obstetric emergencies improve neonatal outcome? BJOG 2006;113:177-82.

43 Lenguerrand E, Winter C, Siassakos D, et al. Effect of handson interprofessional simulation training for local emergencies in Scotland: the thistle stepped-wedge design randomised controlled trial. BMJ Qual Saf 2020;29:122-34.

44 Sørensen JL, Løkkegaard E, Johansen M, et al. The implementation and evaluation of a mandatory multi-professional obstetric skills training program. Acta Obstet Gynecol Scand 2009;88:1107-17.

45 Crofts JF, Fox R, Draycott TJ, et al. Retention of factual knowledge after practical training for intrapartum emergencies. Int $J$ Gynaecol Obstet 2013;123:81-5.
46 Crofts JF, Bartlett C, Ellis D, et al. Management of shoulder dystocia: skill retention 6 and 12 months after training. Obstet Gynecol 2007;110:1069-74.

47 Nelissen E, Ersdal H, Mduma E, et al. Helping mothers survive bleeding after birth: retention of knowledge, skills, and confidence nine months after obstetric simulation-based training. BMC Pregnancy Childbirth 2015;15:190.

48 Draycott TJ, Collins KJ, Crofts JF, et al. Myths and realities of training in obstetric emergencies. Best Pract Res Clin Obstet Gynaecol 2015;29:1067-76.

49 Siassakos D, Fox R, Bristowe K, et al. What makes maternity teams effective and safe? Lessons from a series of research on teamwork, leadership and team training. Acta Obstet Gynecol Scand 2013;92:1239-43.

50 Lilja F, Mani K, Wanhainen A. Editor's choice - trend-break in abdominal aortic aneurysm repair with decreasing surgical workload. Eur J Vasc Endovasc Surg 2017;53:811-9.

51 Meyer L, Stubbs B, Fahrenbruch C, et al. Incidence, causes, and survival trends from cardiovascular-related sudden cardiac arrest in children and young adults 0 to 35 years of age: a 30 -year review. Circulation 2012;126:1363-72.

52 Nayahangan LJ, Lawaetz J, Strøm M, et al. Ensuring competency in open aortic aneurysm repair - development and validation of a new assessment tool. Eur J Vasc Endovasc Surg 2020;59:767-74. 